\title{
NEWS AND ANNOUNCEMENTS
}

ADSA Member News ...

\section{National Association of Animal Breeders (NAAB) Research Award}

The National Association of Animal Breeders (NAAB) has announced that nominations for the 2014 NAAB Research Award will be accepted until and must be received by December 15, 2013. Anyone who is interested in or associated with the artificial insemination industry or research and education related to the artificial insemination industry, animal physiology, or animal breeding may submit nominations for prospective research award recipients. Nomination forms may be obtained after October 1 from NAAB, PO Box 1033, Columbia, Missouri 65205 (phone: 573/445-4406; e-mail: naab-css@naab-css.org). Note: This award will only be presented in the even years, in conjunction with the NAAB Biennial Technical Conference.

Basic qualifications of nominees for the NAAB Research Award are as follows:

1. Shall have made a significant contribution to the science of artificial insemination, physiology, or animal breeding in the United States.

2. Based on, but not limited to original published research and teaching. Cumulative contribution of the nominee's research to the AI industry to be a primary consideration.

3. Shall not have previously received the NAAB Research Award.

4. Must be living and currently active in his or her field of work at the time of nomination.

5. Nominees are not required to be US citizens.

The award will consist of an attractive plaque and $\$ 2,500.00$ from NAAB. Presentation of the award will be made at the NAAB Annual Convention in September 2014.

\section{Upcoming Publication}

Milk and Dairy Products in Human Nutrition: Production, Composition and Health, edited by Young W. Park and George F. W. Haenlein. Wiley-Blackwell, Oxford, UK. Hardcover, 728 pages, US $\$ 215.00$. ISBN: 978-0-470-67418-5.

This comprehensive reference is the first to address a wide range of topics related to milk production and human health, including mammary secretion, production, sanitation, quality standards and chemistry, as well as nutrition, milk allergies, lactose intolerance, and the bioactive and therapeutic compounds found in milk and dairy products. Unlike other books published in the field, this volume is comprehensive and inclusive for all dairy species of economic importance worldwide. The editors have assembled a team of internationally renowned experts to contribute to this exhaustive volume, which will be essential reading for dairy scientists, nutritionists, food scientists, allergy specialists, health professionals, and consumers of dairy foods.

\section{Positions Available . . .}

The deadline for the submission of position announcements for publication in the Journal of Dairy Science is the 25th day of the month, two months preceding the month of issue. For example, ads submitted by May 25 will be printed in the July issue of the journal.

Fees for ads are based on membership in the American Dairy Science Association or the American Society of Animal Science. For members, the flat fee is $\$ 150$; for others, $\$ 250$. We do not accept display ads. Ads from agencies are not commissionable.

Position announcements should be electronically submitted, using the form on the Federation of Animal Science Societies (FASS) Web site, http://www.fass.org/job.asp, for publication in the printed version of the journal and online at the FASS Job Resource Center. Ads that appear in the printed version will automatically be posted online at no extra charge. Ads that are received past the deadline will appear only on the Web site.

If electronic submission is impossible, ads can be e-mailed to fass@assochq.org. Ads should be formatted as a single paragraph; complete sentences should be used. Advertisers will receive an invoice after the ad is posted or published; those who meet print publication deadline will receive a tearsheet with the invoice.

For more job placement announcements, please see the FASS Job Resource Center at www.fass.org/

- Assistant/Associate Professor Ruminant Nutritionist. University of California-Davis has an opening for an assistant/associate professor in ruminant nutrition preferably with emphasis in ruminant microbiology with teaching, research and outreach responsibilities. The appointment is in the Department of Animal Science in the College of Agricultural and Environmental Sciences and is an academic year (9-month) tenure track assistant/associate professor position. The successful candidate will establish a research program focused on improving sustainable animal production focused on enhancing efficiency of food production, nutrient retention, and qualities of human food products and the effect of the gut microbiome population and/or function in this system. 
The Department focuses on the creation, development and distribution of basic and applied knowledge related to the biology and production of domestic animals, ranging in scope from the molecular to the ecosystem level (http://animalscience.ucdavis.edu). Department of Animal Science faculty conduct nationally and internationally recognized research related to farm animals but also study wild, laboratory, and companion animal species. Fields of study within the Department include all aspects of animal biology with a strong focus on physiology, systems modeling, nutrition, genetics, and behavior. The University of California College of Agricultural \& Environmental Sciences is a premier agricultural school worldwide. The appointee will have access to a range of animal and infrastructure resources and many collaborative opportunities within the Department and with colleagues in other units including the School of Medicine and the School of Veterinary Medicine.

The appointee is expected to establish a competitively funded research program in the area of nutrient use for ruminant production and utilizing, and where appropriate the importance of rumen microbiology in this process. This research may encompass molecular to organismal levels of organization. The appointee will be responsible for contributing to the curriculum within the Department including teaching undergraduate courses in nutrition and biochemistry as assigned by the department chair. Mentoring of graduate students, undergraduate student advising, participation in and development of outreach programs, curricular development, and performance of Departmental and University service are expected. The appointee is expected to conduct fundamental research yielding basic biological mechanisms and translatable outcomes, to train students, and to provide mission-oriented research and outreach relevant to the California Agricultural Experiment Station that will ultimately support the economic viability of California's animal industries.

A PhD or equivalent degree (postdoctoral experience is preferred) in ruminant nutrition is required, preferably with emphasis in rumen microbiology or related field with interest in enhancing efficiency of food production, nutrient retention, and qualities of human food products and the effect of the gut microbiome population and/or function in this system. The research is expected to have application to production animals. Evidence of research excellence is expected. The candidate should have the ability to develop and instruct undergraduate and graduate courses, and to design and conduct extramurally funded research relevant to sustainable animal production and health.
Salary will be commensurate with experience within the assistant/associate professor ranks at the University of California.

Application materials must be submitted via the following website: https://recruit.ucdavis.edu/apply/ JPF00104. The position will remain open until filled. To ensure consideration, applications should be received by October 1, 2013. Materials requested to include: (1) curriculum vitae, (2) publications list, (3) up to three publications, (4) transcripts if the applicant is within five years of degree, (5) statement of research accomplishments, (6) statement of teaching accomplishments and philosophy, (7) statement of future research plans relevant to ruminant nutrition with emphasis in rumen microbiology, and (8) the names, addresses, including e-mail, of three professional references. Additional inquiries should be directed to Professor Ed DePeters, Recruitment Advisory Committee Chair, Department of Animal Science, One Shields Avenue, University of California, Davis, CA 95616; phone: (530) 752-1263; e-mail: ejdepeters@ucdavis.edu.

UC Davis is an affirmative action/equal employment opportunity employer and is dedicated to recruiting a diverse faculty community. We welcome all qualified applicants to apply, including women, minorities, veterans, and individuals with disabilities.

- Assistant/Associate Professor-Functional Genomics/Systems Biology. The Department of Poultry Science at Texas A\&M University is seeking an assistant professor/associate professor in avian genomics/systems biology. This 10-month tenure track position will have both teaching and research responsibilities. The successful applicant will conduct genomic research on some aspect of poultry biology of health or economic consequence and develop an independent research program that is nationally and internationally competitive. Research themes might include embryology, immune function, poultry health, food safety or other relevant topics able to operate within a One Health context. The incumbent will be expected to collaborate with other scientists on related projects. A demonstrated ability to obtain extramural funding is an asset and publication track record essential. Teaching responsibilities will involve two courses, one within the undergraduate program and one within the graduate program related to some aspect of applied avian genomics. Other responsibilities will include graduate student advising and service on university committees.

Applicants must have a $\mathrm{PhD}$ or equivalent degree in a field related to genetics, genomics, systems or developmental biology with training in bioinformatics and computational biology. The successful applicant's 
combined background experiences should emphasize genetics, epigenetics, functional genomics, and/or biotechnology as it relates to poultry biology. A demonstrated ability to apply fundamental molecular biology and genomic tools to assist the poultry or animal industry will be an asset.

Applicants should submit a letter of application, $\mathrm{CV}$, statements of research and teaching interests, and names with contact information for three references to: Dr. Rosemary Walzem, Professor, Department of Poultry Science, 101 Kleberg Center, 2472 TAMU, College Station, Texas 77843-2472. Review of applications will begin June 1, 2013, and will continue until the position is filled. For more information, visit http://posc. tamu.edu or contact Dr. Walzem at 979-845-1931 or rwalzem@poultry.tamu.edu.

Employment with the Texas A\&M University System and in any of its sponsored programs is open to qualified individuals regardless of race, color, religion, sex, age, national origin, or educationally unrelated handicaps. Texas A\&M University and the Texas AgriLife Extension Service are equal opportunity employers. Texas A\&M University strives to have an excellent faculty, student body, learning environment and community that embraces diversity in all its forms.

- Assistant Specialist in Cooperative Extension for Urban Agriculture and Food Safety. The Department of Population Health and Reproduction, School of Veterinary Medicine, University of California, Davis, has an opening for an assistant specialist in Cooperative Extension for Urban Agriculture and Food Safety. The University of California Cooperative Extension (UCCE), a statewide program with local delivery, is seeking a full-time assistant specialist in cooperative extension (50\%) and assistant in the Agricultural Experiment Station (50\%) in the area of preharvest microbial food safety for the growing segment of California farmers who retail directly to their local public through farmers markets and related venues such as community-supported agriculture. The successful candidate will collaborate closely with colleagues in the School, across the University, and within the network of Cooperative Extension who work on the health of herds and flocks, food safety, manure management, and the agricultural production environment.

Salary will be dependent on qualifications and experience. A PhD or equivalent degree in microbiology, epidemiology, or food science is required, and a DVM or equivalent is preferred. The successful candidate will have expertise or training in diagnostic microbiology of food safety pathogens, small-scale animal production agriculture, and a demonstrated ability or potential to develop intervention strategies that reduce the dis- semination of microbial pathogens in the preharvest production environment. A research record emphasizing microbiology of foods of animal origin, given the higher microbial threats associated with commodities such locally processed meats, eggs, milk, and cheese, is essential. A record of acquisition of extramural funding or the potential to do so is required. Excellent interpersonal and communication skills and a demonstrated ability to work with others in a collegial team atmosphere are required. Evidence of or potential for leadership and initiative is required. Evidence of or potential for extending applied research and conducting outreach education is require.

Outreach responsibilities: (1) build food safety capacity in collaboration with the network of UCCE Advisors and Specialists, farmers markets, communitysupported agriculture, and other direct marketing systems, along with addressing the needs for home and community gardeners; (2) develop and extend sciencebased information on how to minimize the introduction and dissemination of microbial pathogens within the preharvest small farm environment; (3) interact with producers, ranchers, and growers, allied professionals and agricultural organizations, regulatory agencies, and academic clientele such as UCCE Advisors and AES faculty; and (4) participate in the graduate academic programs (MS and $\mathrm{PhD}$ ) of the campus.

Research responsibilities: the development of a creative and productive research program performed independently and collaborative with UCCE Advisors, with funding from extramural sources is a fundamental and indispensable requirement of the position, including publication of results in peer-reviewed professional and scientific journals and appropriate UCCE outlets. In order to complement the Department's existing strengths in microbial genomics and metabolomics, epidemiology and environmental health, and livestock/ poultry population health, the successful candidate will identify key sources of microbial pathogens and modes of transmission into the agricultural production environment, identify critical control points to reduce the occurrence of microbial pathogens in food animals and their products, and develop good agricultural practices that minimize the pathogen contamination of raw product prior to harvest. This individual will provide leadership in directing research projects of professional and graduate students.

Service responsibilities: University and public service through committee work, participation in professional organizations, continuing education and other appropriate means is required.

To receive fullest consideration, applications must be submitted by September 30, 2013; position will remain open until filled. To begin the application process, in- 
terested applicants should register online at https:// recruit.ucdavis.edu and submit the following materials: (1) a letter of intent outlining special interest in the position, overall related qualifications and experience and career goals; (2) curriculum vitae; and (3) the names and addresses of four professional references.

The University of California, Davis and the Department of Population Health and Reproduction, School of Veterinary Medicine, are interested in candidates who are committed to the highest standards of scholarship and professional activities, and to the development of a campus climate that supports equality and diversity. The University of California is an affirmative action/ equal opportunity employer.

- Research Scientist/Manager. Lallemand is a leading company in the selection, production, and marketing of yeast and bacteria-based solutions for nutrition and health businesses. In order to strengthen our animal nutrition research and technical teams, we are seeking a scientist who will lead a new program in conjunction with the William H. Miner Agricultural Research Institute focusing on silage research. The successful candidate will undertake research towards the screening and development of new microbial strains with properties important to improving the efficacy of forage fermentation and stability during storage and feed-out phases; develop and lead a research program to meet the needs of the business unit; work with management team and scientists to direct the research required and to accomplish this program; perform library searches and literature reviews to support the research program; provide technical support and present scientific data for the marketing and commercial teams; and attend and present data at appropriate research conferences to consolidate the marketing and sales of our products.

$\mathrm{A} \mathrm{PhD}$ in animal sciences is required, preferably with postdoctoral and recent research experience in silage fermentation and quality, and microbiology. Experience with molecular biology techniques will also be required. Proficiency in the use of computer software such as SAS (or other leading statistical software), Excel, Word, and other standard software packages as needed. Proficiency in speaking and writing English; multi-lingual capability (Spanish and French) is preferred. The candidate should demonstrate capacity for critical and integrative thinking, creativity, excellent organizational skills, proactive and have passion for science.

Salary is commensurate with qualifications and experience. An attractive benefits package is available.

Please send your application at the attention of Dr. Renato Schmidt via e-mail: rschmidt@lallemand.com.

For more job position announcements, please see the FASS Job Resource Center at http:// www.fass.org/job.asp. 